\title{
Open-label placebo treatment in chronic low back pain: a randomized controlled trial
}

\section{Citation}

Carvalho, Cláudia, Joaquim Machado Caetano, Lidia Cunha, Paula Rebouta, Ted J. Kaptchuk, and Irving Kirsch. 2016. "Open-label placebo treatment in chronic low back pain: a randomized controlled trial." Pain 157 (12): 2766-2772. doi:10.1097/j.pain.0000000000000700. http:// dx.doi.org/10.1097/j.pain.0000000000000700.

\section{Published Version}

doi:10.1097/j.pain. 0000000000000700

\section{Permanent link}

http://nrs.harvard.edu/urn-3:HUL.InstRepos:29626027

\section{Terms of Use}

This article was downloaded from Harvard University's DASH repository, and is made available under the terms and conditions applicable to Other Posted Material, as set forth at http:// nrs.harvard.edu/urn-3:HUL.InstRepos:dash.current.terms-of-use\#LAA

\section{Share Your Story}

The Harvard community has made this article openly available.

Please share how this access benefits you. Submit a story.

\section{Accessibility}




\title{
Open-label placebo treatment in chronic low back pain: a randomized controlled trial
}

\author{
Cláudia Carvalho ${ }^{\mathrm{a}, \star}$, Joaquim Machado Caetano ${ }^{\mathrm{b}}$, Lidia Cunha ${ }^{\mathrm{c}}$, Paula Rebouta ${ }^{\mathrm{c}}$, Ted J. Kaptchuk ${ }^{\mathrm{d}}$, Irving Kirsch ${ }^{\mathrm{d}}$
}

\begin{abstract}
This randomized controlled trial was performed to investigate whether placebo effects in chronic low back pain could be harnessed ethically by adding open-label placebo (OLP) treatment to treatment as usual (TAU) for 3 weeks. Pain severity was assessed on three 0- to 10-point Numeric Rating Scales, scoring maximum pain, minimum pain, and usual pain, and a composite, primary outcome, total pain score. Our other primary outcome was back-related dysfunction, assessed on the Roland-Morris Disability Questionnaire. In an exploratory follow-up, participants on TAU received placebo pills for 3 additional weeks. We randomized 97 adults reporting persistent low back pain for more than 3 months' duration and diagnosed by a board-certified pain specialist. Eighty-three adults completed the trial. Compared to TAU, OLP elicited greater pain reduction on each of the three 0- to 10-point Numeric Rating Scales and on the 0- to 10-point composite pain scale $(P<0.001)$, with moderate to large effect sizes. Pain reduction on the composite Numeric Rating Scales was 1.5 (95\% confidence interval: 1.0-2.0) in the OLP group and 0.2 (-0.3 to 0.8) in the TAU group. Openlabel placebo treatment also reduced disability compared to TAU $(P<0.001)$, with a large effect size. Improvement in disability scores was $2.9(1.7-4.0)$ in the OLP group and $0.0(-1.1$ to 1.2) in the TAU group. After being switched to OLP, the TAU group showed significant reductions in both pain $(1.5,0.8-2.3)$ and disability $(3.4,2.2-4.5)$. Our findings suggest that OLP pills presented in a positive context may be helpful in chronic low back pain.
\end{abstract}

\section{Introduction}

Low back pain (LBP) causes more disability than any other medical condition worldwide. ${ }^{2,31}$ It is the most common occupational disorder globally ${ }^{30}$ and, in the United States, is ranked third among all diseases by disability-adjusted lifeyears. ${ }^{24}$ Researchers and clinicians have identified a pressing need for innovative treatments and management tools. ${ }^{11}$

Recent studies have demonstrated that some commonly prescribed front-line therapies for LBP are actually not superior to placebo controls in double-blind randomized clinical trials $(\mathrm{RCTs})^{22,33}$ or are of only marginal increased efficacy. ${ }^{26}$ In themselves, placebo responses in trials for LBP can be large and clinically significant. ${ }^{5,10}$ Undoubtedly, some of these improvements are due to normal waxing and waning of symptoms and regression to the mean. ${ }^{27}$ Recent evidence suggests that beyond such spontaneous improvement,

Sponsorships or competing interests that may be relevant to content are disclosed at the end of this article.

a ISPA_Instituto Universitário de Ciências Psicológicas, Sociais e da Vida, Department of Clinical and Health Psychology, Lisbon, Portugal, ${ }^{b}$ Nova Medical School_Faculdade de Ciências Médicas, da Universidade Nova de Lisboa, Lisbon, Portugal, ${ }^{\circ}$ Unidade de Terapia de Dor do Hospital de Egas Moniz, Centro

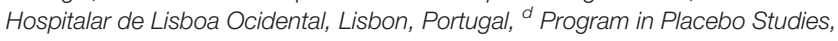
Beth Israel Deaconess Medical Center, Harvard Medical School, Boston, MA, USA

${ }^{*}$ Corresponding author. Address: ISPA_Instituto Universitário de Ciências Psicológicas, Sociais e da Vida, Rua Jardim do Tabaco, 34, 1140-041 Lisbon, Portugal. E-mail address: Claudia.carvalho@ispa.pt (C. Carvalho).

PAIN 157 (2016) 2766-2772

(C) 2016 International Association for the Study of Pain. This is an open-access article distributed under the terms of the Creative Commons Attribution-Non CommercialNo Derivatives License 4.0 (CCBY-NC-ND), where it is permissible to download and share the work provided it is properly cited. The work cannot be changed in any way or used commercially without permission from the journal.

http://dx.doi.org/10.1097/j.pain.0000000000000700 a significant percentage of these responses are due to placebo effects: ie, the psychosocial effects of the therapeutic encounter, including its interactions, rituals, and symbols. ${ }^{18}$

Administrating fake pills to harness placebo effects poses an ethical conundrum for physicians in clinical practice due to the widespread belief that deception is necessary for placebo pills to work (eg, pretending sugar pills are drugs or, more commonly, giving genuine medications that have no known effect on the condition). ${ }^{29}$ However, 4 studies have directly tested the effect of an open-label placebo (OLP) prescription, and all indicated that patients reported benefits after taking pills presented honestly as placebos. Three were small pilot studies. ${ }^{19,25,28}$ The fourth was a controlled trial in irritable bowel syndrome and showed significant, clinically meaningful benefits over no-treatment controls. ${ }^{17}$

The received wisdom is that clinical administration of a placebo requires deception (or double-blind conditions) to be effective. How is it that a placebo treatment is able to produce effects even when the participants know that the pill is inert? One possibility is that the positive rationale with which the placebo was presented was convincing enough to allow participants to suspend their disbelief. ${ }^{21}$ Participation in the study and then in the follow-up for TAU participants implies a belief or hope that the treatment might be helpful. Engendering hope when participants feel hopeless about their condition can be therapeutic. ${ }^{8}$ Although placebo analgesia has been associated with expectancy, ${ }^{21}$ it is possible that pill-taking, including bodily sensations such as twisting bottle tops and swallowing, can produce associations of placebo analgesia independent of conscious expectancies. ${ }^{1}$ Consistent with that hypothesis, recent evidence suggests that nonconscious processes actively contribute to placebo responses. ${ }^{15,16}$ It is also possible that spontaneous fluctuations in pain might be interpreted as evidence that the placebo is working, thereby strengthening expectations of relief and setting in motion a benign cycle between expectancy and change. ${ }^{20}$ 
The goal of this study was to investigate whether adding OLP to treatment as usual (TAU) could benefit patients with chronic low back pain (CLBP) compared to TAU that controlled for additional spontaneous improvement, regression to the mean and the patient-provider relationships.

\section{Methods}

\subsection{Study design}

Between November 2013 and December 2015, we conducted a 3-week RCT comparing current treatment plus OLP to current treatment alone (TAU), in an outpatient pain unit of a general public hospital in Lisbon, Portugal. As a retention device, we offered participants in the TAU group the opportunity to take placebo pills for 3 weeks at the conclusion of the main study. We followed these participants as an exploratory secondary outcome. Written informed consent was obtained from each participant before participation in the study. The Comissão de Ética do Centro Hospitalar de Lisboa Ocidental (Western Lisbon Hospital Centre's Ethics Committee) approved the design and informed consent.

\subsection{Study population}

Participants were recruited from advertisements for "a novel mind-body clinical study of chronic low back pain" in flyers, posters, Facebook posts, magazine advertising, and referrals from health care professionals. Participants were included if they were $\geq 18$ years old and had persistent lower back pain for more than 3 months' duration. Diagnosis was confirmed by a nurse practitioner (P.R.) and a board-certified pain specialist (L.C.). Participants were excluded if they were medicated with opioids in the prior 6 months or had a history of refusing to take oral medication. Because the study was a proof-of-concept, we thought that inclusion of these subpopulations might render our goal more difficult. To reduce potential heterogeneity from different causes of pain, we excluded patients with cancer, fractures, infections, prior lower back surgery, and disk degeneration due to ageing or trauma. We also excluded conditions that make the treatment difficult (eg, paralysis, psychosis) and other conditions that might confound treatment effects or interpretation of results (eg, severe fibromyalgia, rheumatoid arthritis, concurrent care from other providers). Any surgery within the past 30 days, pregnancy, breastfeeding, concurrent legal issues, and participation in another clinical study were also excluding factors.

Participants were allowed to continue their cLBP medications (eg, paracetamol, nonsteroidal anti-inflammatory drugs [NSAIDs], etc) as long as they agreed to not change their medication routine or dosage during the trial, nor make any major life-style changes (eg, starting a new diet or changing their exercise pattern) during the study.

\subsection{Intervention}

The principal investigator (PI) (C.C.) screened telephone and e-mail inquiries and told potential enrollees that participants would be enrolled in a clinical trial to test a novel mind-body treatment approach for cLBP. During screening, the PI checked for inclusion and exclusion criteria, after which the first face-toface appointment at the pain unit was scheduled. Before randomization, all participants first met a registered nurse practitioner (P.R.) for a medical history examination and then with a board-certified pain specialist (L.C.). Participants were then informed by the PI that if they agreed to participate in the study they would be randomized to take placebo pills (OLP) or to a treatment-as-usual (TAU) group for 3 weeks and that the latter would be offered the opportunity to take the placebo pills after the first 3 weeks. We offered this opportunity to the TAU group so that they would not be disappointed in not receiving the intervention and perhaps produce nocebo effects. The PI explained that the placebo pill was an inactive substance, like a flour pill, that contained no active medication in it. After informed consent, all participants were asked if they had heard of the "placebo effect" and explained in an approximately 15-minute a priori script, adopted from an earlier OLP study, ${ }^{18}$ the following "4 discussion points": (1) the placebo effect can be powerful, (2) the body automatically can respond to taking placebo pills like Pavlov dogs who salivated when they heard a bell, (3) a positive attitude can be helpful but is not necessary, and (4) taking the pills faithfully for the 21 days is critical. All participants were also shown a video clip (1 minute 25 seconds) of a television news report, in which participants in an OLP trial of irritable bowel syndrome were interviewed (excerpted from: http://www.nbcnews. com/video/nightly-news/40787382\#40787382).

After these interactions, a sequentially numbered, opaque, sealed randomization envelope that contained treatment assignment was opened. Up to this point, the participant-provider interaction-including delivering the positive rationale and the explanation of the importance of both groups-was the same for all participants. Participants randomized to the OLP group were given a typical prescribed medicine bottle of placebo pills with a label clearly marked "placebo pills" and "take 2 pills twice a day." The placebo pills were Swedish Orange gelatin capsules filled with microcrystalline cellulose, a common inert excipient for pharmaceuticals (Bial, Porto, Portugal). Participants in TAU were reminded of the importance of the control group and of the opportunity to receive placebo pills after the first 3 weeks.

The midpoint (day 11) visit was brief (approximately 10-15 minutes) and included an assessment administered by the registered nurse, who was blind to treatment assignment. This was followed by a brief conversation with the PI, who reminded participants receiving placebo pills about the 4 discussion points and reminded participants in the TAU arm that they could start the placebo pills at the end of the 3 weeks and thanked them for helping make a successful study. All interactions were in a context of a warm supportive participant-provider relationship.

\subsection{Randomization}

Randomization was prepared in advance by a research assistant using a computerized program ("Research Randomizer") and then inserted in a numbered, opaque, sealed envelope. Randomization was revealed to the PI and the participant during the first visit, after discussion of the 4 points. A registered nurse (P.R.) blinded to treatment assignment conducted all assessments.

\subsection{Outcome assessments}

During baseline interviews, we obtained data on participant demographics, including age, gender, years of education, employment status, current pain medication, and complementary medicine usage (Table 1). Outcomes were measured at baseline and after 11 and 21 days using paper and pencil questionnaires. Participants on the TAU arm who agreed to participate in a 3-week OLP follow-up responded again to the questionnaires 21 days later. There was no midterm visit during the 3-week open-label follow-up.

Following validated procedures in research on CLBP, our a priori primary outcomes were a change from baseline at 
Table 1

Baseline characteristics of eligible participants.

\begin{tabular}{|c|c|c|}
\hline Characteristic & $\begin{array}{l}\text { Treatment as } \\
\text { usual }(n=42)\end{array}$ & $\begin{array}{l}\text { Open-label } \\
\text { placebo }(n=41)\end{array}$ \\
\hline Mean (SD) age in y & $44.1(13.7)$ & $44.4(13.2)$ \\
\hline Women & $30(71.4)$ & $29(70.7)$ \\
\hline Years (SD) of schooling & $13.3(4.8)$ & $13.5(5.3)$ \\
\hline Employed & $30(71.4)$ & $31(75.6)$ \\
\hline Pain medication use in past week & $37(88.1)$ & $35(85.4)$ \\
\hline Taking NSAIDs/analgesic medication & $34(80.9)$ & $30(73.1)$ \\
\hline Taking antidepressants & $9(21.4)$ & $10(24.4)$ \\
\hline Taking benzodiazepines & $3(7.1)$ & $10(24.4)$ \\
\hline $\begin{array}{l}\text { Taking adjuvant medication for pain } \\
\text { (eg, thiocolchicoside, gabapentin, } \\
\text { cyclobenzaprine) }\end{array}$ & $16(38.0)$ & $17(41.5)$ \\
\hline $\begin{array}{l}\text { Taking dietary supplements } \\
\text { (glucosamine, vitamins, etc) }\end{array}$ & $2(4.8)$ & $4(9.8)$ \\
\hline $\begin{array}{l}\text { Using complementary medicine for } \\
\text { pain relief }\end{array}$ & $9(21.4)$ & $3(7.3)$ \\
\hline $\begin{array}{l}\text { Kept in bed, lying down, or absence } \\
\text { from work or school } \geq 1 \mathrm{~d}\end{array}$ & $15(41.4)$ & $19(46.3)$ \\
\hline Mean (SD) minimum pain & $2.2(1.7)$ & $3.4(1.9)$ \\
\hline Mean (SD) usual pain & $4.8(1.8)$ & $5.0(1.7)$ \\
\hline Mean (SD) maximum pain & $7.0(1.7)$ & $7.1(1.5)$ \\
\hline Mean (SD) disability (RQD score) & $8.5(4.6)$ & $9.9(5.2)$ \\
\hline Mean (SD) bothersomeness & $5.6(2.3)$ & $6.0(2.1)$ \\
\hline
\end{tabular}

Values are represented as numbers (percentages) of participants unless stated otherwise. Binary variables indicate the number (percentage) for whom the response is "yes."

3 weeks in lower back pain intensity during the prior week and dysfunction related to lower back pain. Pain intensity was assessed by asking participants to rate their pain using 3 standard Numeric Rating Scales, ranging from 0 ("no pain") to 10 ("worst pain imaginable"), scoring maximum pain, minimum pain, and usual pain. The mean of the 3 measures was our primary pain outcome. Our other primary outcome was backrelated dysfunction, which was measured using the validated Portuguese adaptation of the Roland-Morris Disability Questionnaire. ${ }^{23}$ The Roland-Morris Disability Questionnaire includes 24 yes or no statements about difficulties in daily activities, such as difficulties in getting dressed and climbing stairs. The overall score is a sum of positive responses, ranging from 0 to 24 , with a higher score signifying more disability. Our secondary measure was bothersomeness, assessed by asking participants to rate how bothersome their pain has been during the past week on a scale of 0 ("not at all bothersome") to 10 ("extremely bothersome"). ${ }^{6}$

Given the novel nature of the study, after outcome data were gathered at the completion of the 3-week trial, participants were interviewed briefly by the PI and asked the following questions. Participants in the placebo arm were asked: (1) What do you think about the idea of taking placebo pills? (2) Did you expect the placebo to work or were you skeptical? (3) What did you think was in the placebo pills? (4) Any further comments/what have you learned with your participation in this study? Participants in the TAU group were asked: (1) Were you disappointed to be in the treatment-as-usual group? (2) What did you like most and least about the study? (3) Any further comments?

\subsection{Statistical analysis}

This trial was designed prospectively to assess and compare differences between OLP + TAU treatment and TAU. We calculated that we need 96 participants to provide $90 \%$ power to detect a 1-point difference between group changes in the pain scores. We used analysis of covariance (ANCOVA) to test these differences on all outcomes, with pretreatment scores as the covariates. The effect of an independent variable in an ANCOVA with pretreatment scores as the covariate is the same, regardless of whether posttreatment scores or change scores are the dependent variable. For ease of interpretation, we present adjusted mean change scores rather than adjusted mean posttreatment scores. To adjust for dropouts, we used a last value carried forward approach, which implicitly assumes no change from baseline for participants who dropped out. Changes in pain, disability, and bothersomeness during the 3-week followup period among participants in the TAU group were analyzed via paired sample $t$ tests.

\section{Results}

We enrolled participants from November 2013 and December 2015. Figure 1 shows details. A total of 239 people completed telephone and/or e-mail screening, 118 of whom were not eligible or refused to participate, leaving 121 people who attended the enrolment visit. During this visit, 24 people were deemed ineligible or refused to participate. We randomized the remaining 97 participants to OLP or TAU. Seven participants in each group (OLP/TAU) were later found to be ineligible (opioid use 4/3, inability to take medications orally $2 / 1$, changed medications $1 / 2$, pain related to trauma 0/1) and were excluded from the analysis, leaving a sample of 83 participants. Three participants in the OLP group and 4 in the TAU group discontinued at midpoint. We replaced missing data from dropouts using the last observation carried forward method. At baseline, the 2 groups were well balanced with regard to demographics, medication, usual pain, maximum pain, disability, and bothersomeness of the pain (Table 1). Despite proper randomization, the TAU group reported lower baseline minimum pain scores than the OLP group (difference on the 10-point scale 1.25, 95\% confidence interval: $0.41-2.10)$. There were no other significant differences between the 2 groups at baseline. Our data analysis plan included the use of analysis of covariance, which adjusts for baseline differences between individuals and thus provides a statistical control for group differences when randomization does not succeed in producing completely balanced groups on baseline measures.

\subsection{Outcomes at 3 weeks}

Table 2 and Figure 2 show the mean change in outcomes at the end of the 3-week treatment period, adjusted for baseline scores. The 3 pain scores were significantly correlated at baseline and the 3-week endpoint and composite pain scores showed adequate reliability (Cronbach alpha $=0.70$ and 0.91 at baseline and endpoint, respectively). Thus, the composite score provides the most reliable measure of pain severity and pain reduction. The ANCOVA on the composite score revealed that compared to TAU, OLP elicited greater pain reduction on the composite pain measure $(P<0.001)$. Open-label placebo also reduced disability compared to TAU $(P<0.001)$, with a large effect size. Differences on bothersomeness were not significant $(P=0.195)$. The ANCOVA also revealed that compared to TAU, OLP elicited significantly greater pain reduction on each of the 3 pain rating 


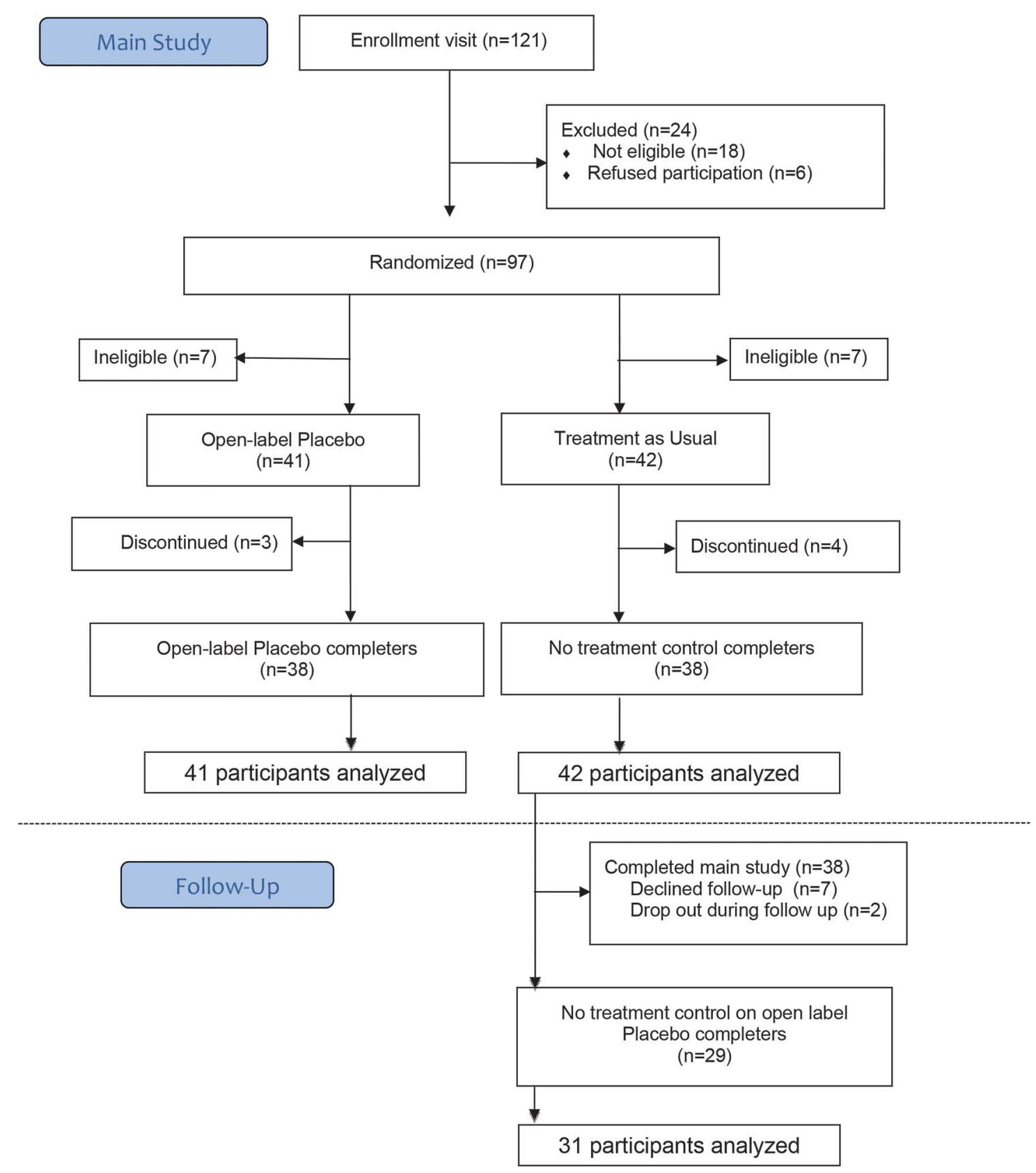

Figure 1. Flow of participants through study.

scales $(P=0.008,0.018$, and 0.040 for minimum, usual, and maximum pain, respectively). Effect sizes ranged from medium $(g=0.46)$ to large $(g=0.76)$.

A reduction in pain of $27.9 \%$ has been found to correspond to clinical ratings of "much improved" and a $30 \%$ reduction has been recommended as an indication clinical significance. ${ }^{7,9}$ There was a clinically significant 30\% reduction in both usual and maximum pain in the placebo group compared to reductions of $9 \%$ and $16 \%$ in usual and maximum pain, respectively, in the continued usual treatment group. Open-label placebo reduced minimum pain by $16 \%$ compared to an increase in pain of $25 \%$ with TAU. There was also a $29 \%$ reduction in pain-related disability in placebo group compared to $0.02 \%$ in the TAU arm.

With 7 dropouts in a total of 83 participants, there is a concern as to whether the use of LOCF might have impacted the results. To address this concern, we conducted a completer analysis.
The results of the completer analysis were consistent with those of the LOCF analysis for all variables (minimum pain, $P=0.004$; usual pain, $P=0.018$; maximum pain, $P=0.017$; composite pain, $P=0.001$; disability, $P=0.001$; and bothersomeness, $P=0.140$ ).

Adverse events were almost nonexistent. At midpoint, 1 OLP participant reported feeling the discomfort she had previously felt on NSAIDs during the first 2 days, but it then disappeared. It is unclear what she meant. At endpoint, 1 participant reported a rash and 1 participant reported an increase in pain when she forgot to take the pills for a couple of days, but said the pain disappeared as soon as she resumed taking pills.

The detailed results of the qualitative checkout questionnaire will be reported elsewhere. Important findings include that participants understood they were taking placebos. Of the 33 OLP participants who responded to the question on the contents 
Table 2

Adjusted mean (SD) improvement and percent changes on outcome measures at 3-week endpoint, with effect sizes and analysis of covariance summary statistics.

\begin{tabular}{|c|c|c|c|c|c|c|c|c|c|}
\hline \multirow[t]{2}{*}{ Outcome } & \multicolumn{2}{|l|}{$\operatorname{TAU}(n=42)^{\star}$} & \multicolumn{2}{|l|}{$\operatorname{OLP}(n=41)$} & \multirow[t]{2}{*}{ Effect size, $g$} & \multicolumn{2}{|c|}{ Mean square } & \multirow[t]{2}{*}{$F_{(1,80)}$} & \multirow[t]{2}{*}{$P$} \\
\hline & Mean (SD) & $\%$ Change & Mean (SD) & $\%$ Change & & Between & Error & & \\
\hline \multicolumn{10}{|c|}{ Pain (10-point scale) } \\
\hline Minimum & $-0.56(1.80)$ & -25 & $0.54(1.73)$ & 16 & 0.62 & 22.60 & 3.03 & 7.45 & 0.008 \\
\hline Usual & $0.44(2.13)$ & 9 & $1.48(1.79)$ & 30 & 0.53 & 21.87 & 3.73 & 5.87 & 0.018 \\
\hline Maximum & $1.12(2.09)$ & 16 & $2.15(2.45)$ & 30 & 0.45 & 21.45 & 4.91 & 4.37 & 0.040 \\
\hline Composite & $0.24(1.61)$ & 5 & $1.49(1.68)$ & 28 & 0.76 & 30.10 & 2.73 & 11.02 & $<0.001$ \\
\hline Disability (RDQ) & 0.02 (3.73) & 0 & $2.86(3.91)$ & 29 & 0.74 & 162.71 & 13.45 & 12.10 & $<0.001$ \\
\hline Bothersomeness* & $0.78(2.61)$ & 14 & $1.44(2.46)$ & 24 & 0.66 & 8.94 & 5.25 & 1.71 & 0.195 \\
\hline
\end{tabular}

${ }^{*} n=41$ in the TAU group, $d f=1,70$ due to missing baseline data for 1 participant

OLP, open-label placebo; RDQ, Roland-Morris Disability Questionnaire; TAU, treatment as usual.

of the pills, 30 reported that "it was not an active substance" (eg, "sugar," "flour," nothing in it," or "what you said it would be"). Three participants reported that the pills were "pain killers" (eg, "it worked so well that it has to contain something"). In response to the question, whether the participants initially thought the treatment would work or were skeptical, of the 30 participants in the OLP, 21 said "skeptical" or "a little," 9 said they believed it would work. In the TAU arm, most respondents were not disappointed about assignment "because I knew I will have it later."

\subsection{Outcomes of TAU participants who took placebo pills after the main study}

At their last treatment session, participants in the TAU group were invited to participate in a follow-up continuation, during which they would receive OLP. Of the 38 TAU participants who completed the main study, 7 declined follow-up OLP, leaving 31 participants entering the follow-up phase. Two of these participants discontinued after entering the follow-up phase. We replaced missing data from these 2 dropouts using the last observation carried forward method. One participant neglected to rate minimum pain at the end of the follow-up. Thus, analyses of minimum pain and composite pain intensity included 30 participants.
Table 3 reports the mean change in outcomes from the end of the 3-week treatment period to the end of the 3-week follow-up. After being given OLP for 3 weeks, participants in TAU who had entered the follow-up showed significant pain relief on all outcome measures ( $P \leq 0.001$ for each), with moderate to large effect sizes. Pain reductions ranged from 1.3 to 1.7 on a 0 to 10 scale. Percent pain reduction ranged from $29 \%$ for maximum pain to $46 \%$ for minimum pain. Back pain-related disability decreased by $40 \%$ and pain bothersomeness decreased by $34 \%$.

\section{Discussion}

The study is the first to demonstrate potential clinically significant benefits of OLP treatment in CLBP. We found that adding OLP to TAU resulted in significantly greater reductions in CLBP and painrelated disability than TAU alone (Table 2). The amount of additional pain reduction produced by OLP was approximately $30 \%$ of baseline pain and disability ratings.

Almost $90 \%$ of the participants in this trial were taking pain medication, primarily NSAIDs, before and during the trial. Although NSAIDs are reported to reduce LBP more than double-blind placebo, the difference amounts to less than 1 point on a 0 to 10 pain scale. ${ }^{26}$ In this study, OLP enhanced pain reduction by 1.49 points on a 0 to 10 scale compared to a 0.24
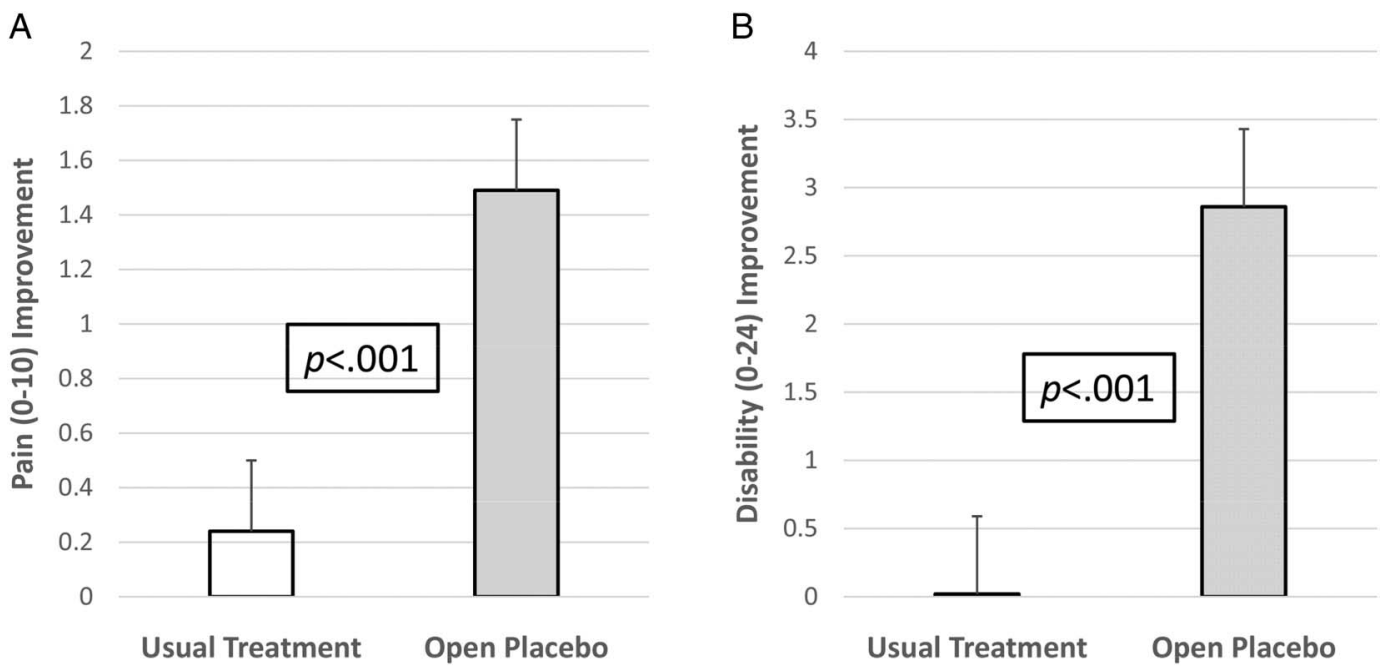

Usual Treatment Open Placebo

Usual Treatment Open Placebo

Figure 2. Outcomes by treatment group at 21-day endpoint. (A) Mean adjusted change scores on the composite pain measure. (B) Mean adjusted change scores on the 24-item Roland-Morris Disability Questionnaire. Error bars represent standard errors of the mean. 
Table 3

Mean (SD) improvement, percent change, and paired sample $t$ test statistics in the TAU group after 3-week treatment with OLP during the follow-up period.

\begin{tabular}{|c|c|c|c|c|c|}
\hline & Mean change $(n=31)$ & $\%$ Change & $t(30)$ & $P$ & Effect size, $g$ \\
\hline \multicolumn{6}{|c|}{ Pain (10-point scale) } \\
\hline Minimum* & $1.30(1.74)$ & 46 & 4.08 & $<0.001$ & 0.75 \\
\hline Usual & $1.68(2.14)$ & 38 & 4.37 & $<0.001$ & 0.79 \\
\hline Maximum & $1.71(2.71)$ & 29 & 3.51 & $<0.001$ & 0.63 \\
\hline Composite* & $1.53(1.98)$ & 36 & 4.24 & $<0.001$ & 0.77 \\
\hline Disability (RQD) & 3.35 (3.22) & 40 & 5.80 & $<0.001$ & 1.04 \\
\hline Bothersomeness & $1.61(2.28)$ & 34 & 3.95 & $<0.001$ & 0.71 \\
\hline
\end{tabular}

${ }^{*} \mathrm{n}=30, \mathrm{df}=29$ due to missing rating of minimum pain for 1 participant.

OLP, open-label placebo; RDQ, Roland-Morris Disability Questionnaire; TAU, treatment as usual.

point change with continued standard treatment without the added placebo. This was an added benefit beyond the effect of continued NSAID and/or other ongoing treatment. These data suggest that patients with cLBP could benefit from the addition OLP to their current treatment regimen. Our study supports earlier studies that suggest a benefit for OLP treatment. ${ }^{17,19,25,28}$ Our findings support the Institute of Medicine position that "placebo conceivably be a form of treatment of pain, especially in light of the shortcoming of other modalities or benefits they bring in their right." 14

Our data suggest that OLP can be a safe and effective adjunct to treatment for cLBP. Only 6 participants who attended an enrollment visit refused participation. Only 3 participants in the open-label group discontinued treatment, and only 2 participants in the TAU group discontinued after beginning OLP treatment during the follow-up. In contrast, 17 participants requested prescriptions for placebo at the end of their participation in the study.

\subsection{Limitations}

This RCT has several limitations. Most importantly, our sample size was relatively small and the trial duration was too short to obtain estimates of long-term effects. Replication with a larger sample size and a longer follow-up is required before our "proofof-principle" study allows for any clinical recommendations. Importantly, it is worth noting that large survey ${ }^{13}$ and focus group research ${ }^{3}$ indicates that participants are amenable to accepting OLP treatments if honestly described and endorsed as a possible benefit by their physicians. Furthermore, given that OLP treatment involves transparency and informed consent, the ethics of open-label is unproblematic. ${ }^{4}$

Our outcome measures were subjective rather than objective. Self-appraised outcomes raise the issue of report bias (eg, wishing to please the experimenter), ${ }^{12}$ and this might be exacerbated in a nonblind design. However, self-reported pain and disability are the standard outcomes assessed in clinical trials of cLBP. We deliberately chose cLBP for this study just because evidence suggests that placebo effects are clinically critical and significant in conditions based on subjective self-assessment. ${ }^{18}$ Furthermore, despite not having objective markers of changes in any pathophysiology, our results are supported by more than 40 neuroimaging studies of pain conditions that suggests that placebo analgesia is, in fact, correlated with objective changes in quantifiable and specific areas of the brain and relevant neurotransmitters. ${ }^{32}$

The results of this trial might not be generalizable to all patients with CLBP. As is typical in clinical trials, exclusion criteria limit generalizability. In addition, advertisement of a "novel mind-body clinical study" may have appealed to individuals who have concerns about conventional medicine and/or are drawn to complementary and alternative approaches. We note, however, that $87 \%$ of the participants were taking conventional pain medications during the week before the entering the trial, whereas only $14 \%$ were using complementary treatments. Also, this form of self-selection bias is present in all clinical trials in which drugs, psychotherapy, or any other form of treatment is advertised.

\section{Conclusions}

Our data suggest that harnessing placebo effects without deception is possible in the context of a plausible rationale. More research on this possibility is warranted in CLBP and other conditions defined by self-appraisal.

\section{Conflict of interest statement}

The authors have no conflicts of interest to declare.

The Foundation for the Science of the Therapeutic Encounter (F-STE) supported C. Carvalho with a postdoctoral grant. Bial (Porto, Portugal) provided placebo pills. T. J. Kaptchuk and I. Kirsch were supported by National Center for Complementary and Integrative Health, U.S. National Institutes of Health Grant 2K24 AT004095; T. J. Kaptchuk also received funding from R01 AT008573, R61AT009306, R01AT005280, and P01 AT006663.

I. Kirsch received a grant from F-STE.

T. J. Kaptchuk and I. Kirsch contributed equally.

\section{Article history:}

Received 1 June 2016

Received in revised form 21 July 2016

Accepted 16 August 2016

\section{References}

[1] Ackerman JM, Nocera CC, Bargh JA. Incidental haptic sensations influence social judgments and decisions. Science 2010;328:1712-15.

[2] Andersson GB. Epidemiological features of chronic low-back pain. Lancet 1999;354:581-5.

[3] Bishop FL, Aizlewood L, Adams AE. When and why placebo-prescribing is acceptable and unacceptable: a focus group study of patients' views. PLoS One 2014;9:e101822.

[4] Blease C, Colloca L, Kaptchuk TJ. Are open-label placebos Ethical? Informed consent and ethical equivocations. Bioethics 2016;30(6): 407-414.

[5] Chaparro LE, Furlan AD, Deshpande A, Mailis-Gagnon A, Atlas S, Turk DC. Opioids compared with placebo or other treatments for chronic low back pain: an update of the Cochrane Review. Spine 2014;39:556-63.

[6] Dunn KM, Croft PR. Classification of low back pain in primary care: using "bothersomeness" to identify the most severe cases. Spine 2005;30: 1887-92. 
[7] Dworkin RH, Turk DC, Farrar JT, Haythornthwaite JA, Jensen MP, Katz NP, Kerns RD, Stucki G, Allen RR, Bellamy N, Carr DB, Chandler J, Cowan P, Dionne R, Galer BS, Hertz S, Jadad AR, Kramer LD, Manning DC, Martin S, McCormick CG, McDermott MP, McGrath P, Quessy S, Rappaport BA, Robbins W, Robinson JP, Rothman M, Royal MA, Simon L, Stauffer JW, Stein W, Tollett J, Wernicke J, Witter J. Core outcome measures for chronic pain clinical trials: IMMPACT recommendations. PAIN 2005;113:9-19.

[8] Eaves ER, Nichter M, Ritenbaugh C. Ways of hoping: navigating the Paradox of hope and despair in chronic pain. Culture, Medicine, and Psychiatry 2015:1-24.

[9] Farrar JT, Young JP Jr, LaMoreaux L, Werth JL, Poole RM. Clinical importance of changes in chronic pain intensity measured on an 11-point numerical pain rating scale. PAIN 2001;94:149-58.

[10] Henschke N, Kuijpers T, Rubinstein SM, van Middelkoop M, Ostelo R, Verhagen A, Koes BW, van Tulder MW. Injection therapy and denervation procedures for chronic low-back pain: a systematic review. Eur Spine $J$ 2010;19:1425-49.

[11] Hoy D, March L, Brooks P, Blyth F, Woolf A, Bain C, Williams G, Smith E, Vos T, Barendregt J. The global burden of low back pain: estimates from the Global Burden of Disease 2010 study. Ann Rheum Dis 2014;73: 968-74.

[12] Hróbjartsson A, Kaptchuk TJ, Miller FG. Placebo effect studies are susceptible to response bias and to other types of biases. J Clin Epidemiol 2011;64:1223-9.

[13] Hull SC, Colloca L, Avins A, Gordon NP, Somkin CP, Kaptchuk TJ, Miller FG. Patients' attitudes about the use of placebo treatments: telephone survey. BMJ 2013;347:f3757.

[14] IOM. Relieving Pain in America. Washington DC: Institute of Medicine of the National Academies, 2011.

[15] Jensen KB, Kaptchuk TJ, Chen X, Kirsch I, Ingvar M, Gollub RL, Kong J. A Neural Mechanism for Nonconscious Activation of Conditioned Placebo and Nocebo Responses. Cerebral Cortex 2015;25:3903-10.

[16] Jensen KB, Kaptchuk TJ, Kirsch I, Raicek J, Lindstrom KM, Berna C, Gollub RL, Ingvar M, Kong J. Nonconscious activation of placebo and nocebo pain responses. Proceedings of the National Academy of Sciences 2012;109:15959-64.

[17] Kaptchuk TJ, Friedlander E, Kelley JM, Sanchez MN, Kokkotou E, Singer JP, Kowalczykowski M, Miller FG, Kirsch I, Lembo AJ. Placebos without deception: a randomized controlled trial in irritable bowel syndrome. PLoS One 2010;5:e15591.

[18] Kaptchuk TJ, Miller FG. Placebo effects in medicine. N Engl J Med 2015; 373:8-9.
[19] Kelley JM, Kaptchuk TJ, Cusin C, Lipkin S, Fava M. Open-label placebo for major depressive disorder: a pilot randomized controlled trial. Psychother Psychosom 2012;81:312-14.

[20] Kirsch I. Changing expectations: A key to effective psychotherapy. Belmont, CA: Brooks/Cole; 1990.

[21] Kirsch I, Kong J, Sadler P, Spaeth R, Cook A, Kaptchuk TJ, Gollub R. Expectancy and conditioning in placebo analgesia: Separate or connected processes? Psychology of Consciousness. Theory, Research, and Practice 2014;1:51-59.

[22] Machado GC, Maher CG, Ferreira PH, Pinheiro MB, Lin C-WC, Day RO, McLachlan AJ, Ferreira ML. Efficacy and safety of paracetamol for spinal pain and osteoarthritis: systematic review and meta-analysis of randomised placebo controlled trials. BMJ 2015;350. h1225;1-13.

[23] Monteiro J, Faísca L, Nunes O, Hipólito J. Roland Morris disability questionnaire-adaptation and validation for the Portuguese speaking patients with back pain [in Portuguese]. Acta Méd Port 2010;23:761-6.

[24] Murray CJ, Abraham J, Ali MK, Alvarado M, Atkinson C, Baddour LM, Bartels DH, Benjamin EJ, Bhalla K, Birbeck G. The state of US health, 1990-2010: burden of diseases, injuries, and risk factors. JAMA 2013;310:591-606.

[25] Park LC, Covi L. Nonblind placebo trial. Arch Gen Psychiatry 1965;12:336-45.

[26] Roelofs P, Deyo RA, Koes BW, Scholten R, Van Tulder MW. Nonsteroidal anti-inflammatory drugs for low back pain. Cochrane Database Syst Rev 2008;1.

[27] Rutherford BR, Mori S, Sneed JR, Pimontel MA, Roose SP. Contribution of spontaneous improvement to placebo response in depression: a metaanalytic review. J Psychiatr Res 2012;46:697-702.

[28] Sandler A, Bodfish J. Open-label use of placebos in the treatment of ADHD: a pilot study. Child Care Health Dev 2008;34:104-10.

[29] Tilburt JC, Emanuel EJ, Kaptchuk TJ, Curlin FA, Miller FG. Prescribing "placebo treatments": results of national survey of US internists and rheumatologists. BMJ 2008;337:a1938.

[30] Violante F, Mattioli S, Bonfiglio R. Low-back pain. In: Lotti M, Bleecker M, editors. Handbook of Clinical Neurology. Vol. 131. Elsevier, 2015. p. 398-410.

[31] Vos T, Flaxman AD, Naghavi M, Lozano R, Michaud C, Ezzati M, Shibuya K, Salomon JA, Abdalla S, Aboyans V. Years lived with disability (YLDs) for 1160 sequelae of 289 diseases and injuries 1990-2010: a systematic analysis for the Global Burden of Disease Study 2010. Lancet 2013;380:2163-96.

[32] Wager TD, Atlas LY. The neuroscience of placebo effects: connecting context, learning and health. Nat Rev Neurosci 2015;16:403-18.

[33] Williams CM, Maher CG, Latimer J, McLachlan AJ, Hancock MJ, Day RO, Lin CWC. Efficacy of paracetamol for acute low-back pain: a doubleblind, randomised controlled trial. Lancet 2014;384:1586-96. 